\title{
Quality of life of patients from a multidisciplinary clinic of inflammatory bowel disease
}

\author{
Guilherme Borgo FICAGNA ${ }^{1}$, Jean Luís DALRI ${ }^{1}$, Everson Fernando MALLUTA ${ }^{2}$, \\ Bruno Lorenzo SCOLARO ${ }^{3}$ and Sueli Terezinha BOBATO ${ }^{4}$
}

Received: 6 July 2019

Accepted: 23 October 2019

\begin{abstract}
Background - Inflammatory bowel disease encompasses pathological entities, the main being Crohn's disease and ulcerative rectocolitis. Both are characterized by chronic inflammation of the intestine. It affects young people of active age, compromising the situation of those patients, especially their quality of life, experiencing a strong deterioration in their clinical condition, from physical to social and emotional aspects. Objective - Evaluate the quality of life of patients assisted in the multidisciplinary reference outpatient clinic for the treatment of inflammatory bowel diseases, through sociodemographic data and specific questionnaires on the disease, evaluating the intestinal and systemic symptoms and the social and emotional aspects. Make a comparison between the two scales used to obtain the data. Methods - A cross-sectional study was carried out in which patients diagnosed with inflammatory bowel disease were evaluated and observed at a reference outpatient clinic for treatment from May 2017 through December 2018. The participants responded to the Socio-demographic and Clinical Protocol, the SF-36 general quality of life questionnaire and the specific Inflammatory Bowel Disease questionnaire, in addition the correlation between the two scales was performed using Pearson's Correlation (metric scale), which data were analyzed by means of descriptive statistics and the significance level adopted was $5 \%(P \leq 0.05)$. The population studied consisted of 71 patients, excluding pregnant or nursing women and patients under 18 years of age. Results - Seventy-one patients participated in the study, with an average age of 46.5 years and standard deviation of $\pm 13.8 ; 45$ patients had Crohn's disease and 26 were diagnosed with ulcerative rectocolitis; $73.2 \%$ were women; $64.8 \%$ married; $8.4 \%$, smokers; $50.7 \%$ reported practising some type of physical activity. A good distribution of patients was observed between the domains of each questionnaire; no low scores were found for quality of life, and systemic symptoms and emotional aspects were those with the lowest scores among the parameters of the Inflammatory Bowel Disease Questionnaire; physical (40.6 \pm 44.4$)$ and emotional aspects (49.5 \pm 46.0$)$ had lower scores among the Short Form-36 domains. The correlation between the two questionnaires proved to be significant. Conclusion - The clinical profile of the patients followed the characteristics of distribution and prevalence of these diseases. The impact of diseases on quality of life was observed in several aspects, especially those related to psychological components. Multidisciplinary follow-up, as well as psychological, social, nutritional and educational support should be considered important determinants to maintain or improve the quality of life of these patients.
\end{abstract}

HEADINGS - Inflammatory bowel diseases. Crohn disease. Proctocolitis. Quality of life.

\section{INTRODUCTION}

Inflammatory bowel diseases (IBD), Crohn's disease (CD) and ulcerative rectocolitis (URC) are all chronic pathologies with varied clinical manifestations. They differ according to the predominant location of the lesions and their extent, the presence or absence of systemic manifestations and complications of the disease, provoking intestinal and extraintestinal symptoms $\mathrm{s}^{(1-2)}$.

The incidence and prevalence of IBD have increased, especially in developed countries, affecting young people in active age and causing an impact on their quality of life $(\mathrm{QOL})^{(3)}$, both in the domains of physical as well as social and emotional aspects.

The influence of biological and psychosocial factors has led several studies to evaluate the QOL of these patients, using validated and specific instruments, such as the Inflammatory Bowel Disease Questionnaire (IBDQ) ${ }^{(4)}$, designed to calculate the impact of such diseases on those patients ${ }^{(5)}$.
Due to the small amount of tests evaluating the impact of IBC on the QOL of the Brazilian population, this study aims at evaluating the changes within the QOL domains of patients with IBD assisted at the reference outpatient clinic, in order to establish their impacts and broaden the vision of management and therapeutic courses.

\section{METHODS}

A cross-sectional observational, descriptive and analytical study, evaluating patients with a diagnosis of inflammatory bowel disease, who responded to the Socio-demographic and Clinical Protocol, the IBDQ quality of life assessment tool and the Short Form 36 Health Survey (SF-36), and evaluation between questionnaires through Pearson's Correlation, which data were analyzed by means of descriptive statistics. All questionnaires used were validated to the Portuguese language ${ }^{(6-7)}$.

Declared conflict of interest of all authors: none

Disclosure of funding: no funding received

${ }^{1}$ Universidade do Vale do Itajaí (UNIVALI), Faculdade de Medicina, Itajaí, SC, Brasil. ${ }^{2}$ UNIVALI, Departamento de Gastroenterologia, Itajaí, SC, Brasil. ${ }^{3}$ UNIVALI, Departamento de Coloproclogia, Itajaí, SC, Brasil. ${ }^{4}$ UNIVALI, Departamento de Psicologia, Itajaí, SC, Brasil.

Corresponding author: Guilherme Borgo Ficagna. E-mail: guilherme.borgo@hotmail.com 
Seventy-one (71) patients with confirmed diagnosis of inflammatory bowel diseases were evaluated from May 2017 through December 2018, all of whom have clinical follow-up at the multidisciplinary reference outpatient clinic for the treatment of inflammatory bowel diseases of the Vale do Itajaí - UNIVALI, where they receive medical, nutritional and psychological follow-up. The study comprised adults over the age of 18 , regardless of sex, race or educational level. Pregnant and nursing women, as well as patients under the age of 18 were excluded. All interviewees were invited to participate in the study and were approached before or after the clinical routine visit, and patients who did not agree to take part in the study were regularly assisted in the same manner, without prejudice to their treatment. Three questionnaires were applied. The socio-demographic and Clinical Protocol, specific for obtaining epidemiological data. The IBDQ, containing 32 closed questions with a scale of answers of seven points, where one means the worse and seven the best quality of life. The questionnaire is divided by domains: intestinal symptoms, systemic symptoms, social aspects, emotional aspects and final general value, each one having its respective score, and the results are divided by quartiles, the first one with the worst scores $=$ bad, the second = regular, the third $=$ good, and the fourth containing the best scores $=$ excellent . The SF-36 is composed of eleven questions divided in the following domains: general health state, functional capacity, physical aspects, emotional aspects, social aspects, pain, vitality and mental health, and their scores were coded, added and converted into a scale from 0 to 100 , being the worst possible condition and the best health state, respectively, submitted to the same division of quartiles of the IBDQ and evaluated in their domains. The questionnaires used are considered easy to understand and were filled out by patients without external assistance.

The correlation between the two scales was performed using Pearson's correlation (metric scale). The significance level adopted was $5 \%(P \leq 0.05)$.

The study protocol was approved by the Ethics Committee in local research (CAAE: 66051717.0.0000.0120) and all patients signed the informed consent form.

\section{RESULTS}

A total of 71 patients were evaluated in the study, out of whom $52(73.2 \%)$ were female; the average age of the patients was $46.5 \pm 3.8$ years; $45(63 \%)$ patients have $\mathrm{CD}$, and $26(37 \%)$ are URC patients; $64.8 \%$ were married; $8.4 \%$ smokers; $60.3 \%$ with average monthly earnings of $1-3$ minimum wages; $50.7 \%$ reported practicing some kind of physical activity.

The results, according to each domain of the specific questionnaires, are shown in TABLE 1. According to the scores obtained from all IBDQ fields, $50(70 \%)$ patients have a good quality of life. Among the SF-36 results, the lowest quality of life scores were evidenced in two out of the eight domains - physical limits and emotional aspects; the average ( $\pm \mathrm{SD}$ ) was $40.6 \pm 44.4$ and $49.5 \pm 46$, respectively, both with values below half of the variation, which ranges from 0 to 100 points. In Pearson's correlation, the results

TABLE 1. Questionnaire scores in each domain.

\begin{tabular}{|c|c|c|c|c|c|}
\hline \multirow{2}{*}{$\begin{array}{l}\text { Variables } \\
\text { IBDQ }\end{array}$} & & \multicolumn{4}{|c|}{ Average \pm SD } \\
\hline & & & & & \\
\hline Intestinal symptons & & \multicolumn{4}{|c|}{$51.9 \pm 12.6$} \\
\hline Systemic symptons & & \multicolumn{4}{|c|}{$22.8 \pm 7.8$} \\
\hline Emotional aspects & & \multicolumn{4}{|c|}{$56.6 \pm 18.3$} \\
\hline Total & & \multicolumn{4}{|c|}{$157.9 \pm 41.7$} \\
\hline \multicolumn{6}{|l|}{ SF-36 } \\
\hline Funcional capacity & & \multicolumn{4}{|c|}{$72.4 \pm 25$} \\
\hline Physical limitations & & \multicolumn{4}{|c|}{$40.6 \pm 44.4$} \\
\hline Emotional aspects & & \multicolumn{4}{|c|}{$49.5 \pm 46.0$} \\
\hline Social aspects & & \multicolumn{4}{|c|}{$64.5 \pm 25.8$} \\
\hline Pain & & \multicolumn{4}{|c|}{$52 \pm 24.7$} \\
\hline Vitality & & \multicolumn{4}{|c|}{$52.4 \pm 24.3$} \\
\hline SF36 & Intestinal symptons & Systemic symptons & Social aspects & Emotional aspects & Total \\
\hline General health & $0.278^{*}$ & $0.206^{\mathrm{ns}}$ & $0.166^{\mathrm{ns}}$ & $0.179^{\mathrm{ns}}$ & $0.206^{\mathrm{ns}}$ \\
\hline Funcional capacity & $0.465 * * *$ & $0.620 * * *$ & $0.661 * * *$ & $0.659 * * *$ & $0.491 * * *$ \\
\hline Physical limitations & $0.519 * * *$ & $0.634 * * *$ & $0.558 * * *$ & $0.610 * * *$ & $0.574 * * *$ \\
\hline Emotional aspects & $0.487 * * *$ & $0.633 * * *$ & $0.546 * * *$ & $0.657 * * *$ & $0.556 * * *$ \\
\hline Social aspects & $0.512 * * *$ & $0.552 * * *$ & $0.389 * * *$ & $0.547 * * *$ & $0.508 * * *$ \\
\hline Pain & $0.571 * * *$ & $0.628 * * *$ & $0.596 * * *$ & $0.607 * * *$ & $0.496 * * *$ \\
\hline Vitality & $0.441 * * *$ & $0.568 * * *$ & $0.376 * * *$ & $0.574 * * *$ & $0.524 * * *$ \\
\hline Mental health & $0.394 * * *$ & $0.501 * * *$ & $0.371 * * *$ & $0.563 * * *$ & $0.488 * * *$ \\
\hline
\end{tabular}

IBDQ: Inflammatory Bowel Disease Questionnaire. SF-36: Short Form 36 Health Survey. $* P<0.05$. $* * * P<0.001$. ns $=P>0.05$. 
between its various components obtained coefficient variation with significant values $(P<0.001)$, except for the correlation with the general health aspect of patients interviewed, being the significant values only in the correlation with the IS $(P<0.05)$, the other domains of the IBDQ resulted in non-significant values in relation to the general health aspect.

The values obtained for each domain of the SF-36 and IBDQ were analyzed and distributed in four ratings - bad, moderate, good and excelent, and are shown in FIGURE 1.

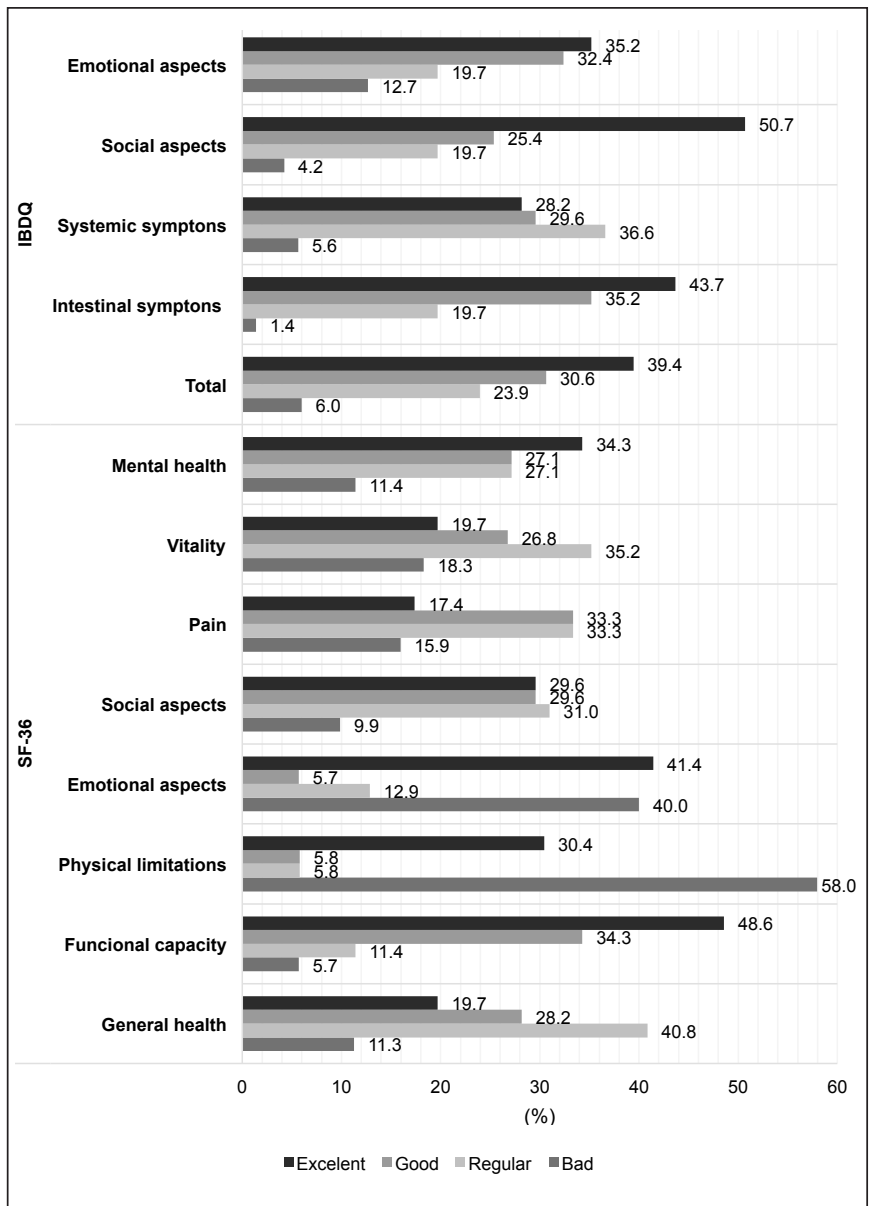

FIGURE 1. Distribution of values found in each questionnaire. IBDQ: Inflammatory Bowel Disease Questionnaire. SF-36: Short Form 36 Health Survey.

\section{DISCUSSION}

The QOL of patients with IBD is influenced by several known factors. The difficulty in quantifying the QOL of the assisted patients led to the elaboration of mechanisms designed for this purpose in order to better intervene therapeutically and create an individualized care plan ${ }^{(8)}$. This study used instruments known and validated in the medical literature, being applied to patients with IBD assisted at the reference outpatient clinic.

IBD have a bimodal characteristic, with incidence in young adults and later in those over 50 years of age. The results of the study showed higher incidence in females $(73.2 \%), \mathrm{CD}$ diagnosis $(63 \%)$, and an average age of patients 46.5 years, slightly above when compared with some studies ${ }^{(1-9)}$ and the regional study of
Cohen et al. ${ }^{(10)}$, who studied 50 patients, also in southern Brazil, with an average age of 42.2 years.

The analysis of the IBDQ showed that $70 \%$ of the patients rated their QOL as "good" or "very good", with an average of 157.9 points and standard deviation of \pm 41.7 points, presenting correlation with current studies, such as Francesconi et al..$^{(1)}$, who obtained an average of 152.7 and 160.9 points, with standard deviation ranging from \pm 39.3 to 46.9 for $C D$ and $U R C$, respectively. Although patients with IBD from different locations present similar scores, they have lower results when compared to the general population. This demonstrates that IBD have an impact on the QOL of patients and reinforces the need to broaden the vision of management and follow the therapeutic course of these pathologies.

The domains social aspects and intestinal symptoms were the most well evaluated, and in the latter there was a higher percentage of classifications as "good" or "very good" (78.9\%). Social aspects correspond to the less affected domain by the patients.

Systemic symptoms and emotional aspects obtained the lowest scores among the evaluations of the four parameters. Emotional aspects, despite being the second domain with the worst score, have shown the highest rates classified as "bad" $(12.7 \%)$. Symptoms such as depressive mood, anxiety and irritability have a high impact on QOL and, according to Teixeira et al. ${ }^{(11)}$, they may emerge as a response to real situations when faced with unpleasant facts. Benvegnú and Tomazoni ${ }^{(9)}$ state that such symptomatology reflects psychological distress, and may exacerbate against the greater activity of the disease.

Batista and Ornellas ${ }^{(12)}$, as well as other studies that correlate the incidence of depressive symptoms with the practice of physical activity, have proved that more physically active people are more protected against depressive disorders or have a lower degree of depression compared to the less active. Groups more vulnerable to the emergence of depressive symptoms should be stimulated to practice more physical activity ${ }^{(13)}$ with the aim of reducing the incidence of depression and thus improve QOL. Since only 50.7\% of the patients interviewed in this study practiced physical activities to some degree, this practice should be strongly encouraged, with the aim of trying to reduce the incidence of depressive conditions, especially for being the population at risk.

In addition, as a potentially useful tool in reducing stress and improving coping methods, patients with IBD may be referred to clinical psychologists specializing in chronic diseases, especially those recently diagnosed with IBD or those who are struggling against the diagnosis. According to Beckman et al. ${ }^{(14)}$, these professionals can assist patients to manage and coexist with IBD by offering education, emotional support and skills to cope with the situation as a form of stress control.

Analyzing the values of each component of the SF-36 score of the patients, there was a variation between each domain, and physical and emotional aspects were those in which lower levels in relation to QOL were the most observed, and these low scores can be explained by the possible psychoemotional alterations of these patients ${ }^{(3)}$.

Among the aspects with the higher scores, the functional capacity of the patients can be highlighted, and this is a factor that directly influences well-being and daily limitations ${ }^{(15)}$, which are fundamental aspects to patients with the disease.

Based on the results of this study, the comparison between the domains of the IBDQ and the SF-36 made through Pearson's correlation $^{(6)}$ demonstrated significant $P$ values between the two 
scores. These significant findings allow to establish the correlation between the two methods analyzed, being good indicators of QOL in patients with IBD.

A regional study ${ }^{(10)}$, as well as others performed with the same purpose, evaluated the QOL of patients with IBD in Southern Brazil. This study reveals the reality of people living with IBD and can encompass its results in comparison with other nationwide studies. Thus, compared to other major analyses conducted nationwide and internationally, it adds important data to the evaluation and reinforces the need for further future research to better understand the QOL of the Brazilian population with IBD.

The importance of including questionnaires that assess the QOL of patients assisted in the routine of medical practice present established benefits ${ }^{(4,10,14)}$. In addition to guiding the need for therapeutic interventions, the use of the right tools can formulate a more appropriate and individualized care plan for patients.

\section{CONCLUSION}

The clinical profile of patients with IBD and the impact of these pathologies on the QOL of the interviewees could be observed in this study. The main domains and components that brought negative impact on the QOL of the interviewees were those related to the emotional aspects and systemic symptoms of inflammatory bowel diseases. In the face of these findings, associated with the more severe repercussions of the diseases and their influence on the QOL, the patients of the outpatient clinic analyzed in this study can benefit from measures of promotion and prevention of crises, as well as psychological, nutritional, social and educational support, considered important determinants to maintain or improve the QOL of patients with IBD. The multidisciplinary follow-up of these patients, as it is performed in the outpatient clinic, involving a team of specialists in gastroenterology, coloproctology, nutrition and psychology, implies positive results in the QOL. Thus, instruments that assess the QOL of patients with IBD have an important role, as they are tools that help health professionals in their conducts and management.

\section{Authors' contribution}

Ficagna GB, Dalri JL: project management. Malluta EF, Scolaro BL, Bobato ST: supervision.

\section{Orcid}

Guilherme Borgo Ficagna: 0000-0001-6018-3070.

Jean Luís Dalri: 0000-0002-0701-6393.

Everson Fernando Malluta: 0000-0001-6554-6280.

Bruno Lorenzo Scolaro: 0000-0001-6277-7075.

Sueli Terezinha Bobato: 0000-0002-1414-6364.

Ficagna GB, Dalri JL, Malluta EF, Scolaro BL, Bobato ST. Qualidade de vida dos pacientes de um ambulatório multidisciplinar de doenças inflamatórias intestinais. Arq Gastroenterol. 2020;57(1):8-12.

RESUMO - Contexto - A doença inflamatória intestinal engloba entidades patológicas, sendo as principais a doença de Crohn e a retocolite ulcerativa. Ambas se caracterizam por inflamação crônica do intestino. Acomete jovens em idade ativa comprometendo a situação desses pacientes, principalmente a qualidade de vida, que sofre uma forte deterioração frente à condição clínica dos portadores, desde aspectos físicos como também sociais e emocionais. Objetivo - Avaliar a qualidade de vida dos pacientes atendidos no ambulatório multidisciplinar de referência para o tratamento de doenças inflamatórias intestinais, através de dados sociodemográficos e de questionários específicos sobre a doença, avaliando os sintomas intestinais e sistêmicos e os aspectos sociais e emocionais. Realizar um comparativo entre os questionários específicos utilizados para obtenção dos dados. Métodos - Realizou-se um estudo de corte transversal em que foram avaliados pacientes com diagnóstico de doença inflamatória intestinal, acompanhados em um ambulatório de referência para o tratamento, entre maio de 2017 e dezembro de 2018. Os participantes responderam ao Protocolo Sociodemográfico e Clínico, ao questionário de qualidade de vida geral SF-36 e ao específico Inflammatory Bowel Disease Questionnaire, além da correlação realizada entre as duas escalas através da Correlação de Pearson (escala métrica), cujos dados foram analisados por meio da estatística descritiva e o nível de significância adotado foi de $5 \%(P \leq 0,05 \%)$. A amostra contou com 71 pacientes, sendo excluídos do trabalho gestantes ou nutrizes e menores de 18 anos. Resultados - Setenta e um pacientes participaram do estudo, com média de idade de 46,5 anos e desvio padrão de $\pm 13,8 ; 45$ eram portadores de doença de Crohn e 26 possuíam o diagnóstico de retocolite ulcerativa; 73,2\% eram mulheres; 64,8\% casados; 8,4\%, fumantes; 50,7\% relataram fazer algum tipo de atividade física. Foi observada boa distribuição dos pacientes entre os domínios de cada questionário; não foram encontrados baixos escores para a qualidade de vida, sendo os sintomas sistêmicos e os aspectos emocionais aqueles com menor pontuação dentre os parâmetros do Inflammatory Bowel Disease Questionnaire; os aspectos físicos $(40,6 \pm 44,4)$ e os emocionais $(49.5 \pm 46.0)$ tiveram menor pontuação entre os domínios do SF-36. A correlação entre os dois questionários mostrou-se significativa. Conclusão - O perfil clínico dos pacientes seguiu as características de distribuição e prevalência dessas doenças. O impacto das doenças na qualidade de vida foi observado em diversos aspectos, principalmente os relacionados aos componentes psicológicos. O acompanhamento multidisciplinar, bem como suporte psicológico, social, nutricional e educacional devem ser considerados importantes determinantes para manter ou melhorar a qualidade de vida desses pacientes.

DESCRITORES - Doenças inflamatórias intestinais. Doença de Crohn. Proctocolite. Qualidade de vida. 


\section{REFERENCES}

1. Calixto RP, Flores C, Francesconi CF. Inflammatory Bowel Disease: Impact on scores of quality of life, depression and anxiety in patients attending a tertiary care center in Brazil. Arq Gastroenterol. 2018;55:202-7.

2. Bonaz BL, Bernstein CN. Brain-gut interactions in inflammatory bowel disease Gastroenterology. 2013;144:36-49.

3. Silva AF, Schieferdecker MEM, Amarante HBMS. Ingestão alimentar em pacientes com doença inflamatória intestinal. ABCD, Arq Bras Cir Dig. 2011;24:204-9.

4. Campolina AG, Ciconelli RM. [SF-36 and the development of new assessment tools for quality of life]. [Article in Portuguese]. Acta Reumatol. 2008;33:127-33.

5. Mitchell A, Guyatt G, Singer J, Irvine EJ, Goodacre R, Tompkins C, et al. Quality of life in patients with inflammatory bowel disease. J Clin Gastroenterol. 1988;10:306-10.

6. Pontes RMA, Miszputen SJ, Ferreira-Filho OF, Miranda C, Ferraz MB. [Quality of life in patients with inflammatory bowel diseases: translation to Portuguese language and validation of the "Inflammatory Bowel Disease Questionnaire" (IBDQ)]. [Article in Portuguese]. Arq Gastroenterol. 2004;41:137-43.

7. Ciconelli RM, Ferraz MB, Santos W, Meinão I, Quaresma MR. Tradução para o português e validação do questionário genérico de avaliação de qualidade de vida "Medical Outcomes Study 36-Item Short-Form Health Survey (SF-36)" Rev. Bras. Reumatol. 1999;39:143-50.

8. Mitchell A, Guyatt G, Singer J, Irvine EJ, Goodacre R, Tompkins C, et al. A new measure of health status for clinical trials in inflammatory bowel disease. Gastroenterology. 1989;96:804-10.
9. Tomazoni EI, Benvegnu DM. Symptoms of anxiety and depression, and quality of life of patients with Crohn's disease. Arq Gastroenterol. 2018;55:148-53.

10. Cohen D, Bin CM, Fayh APT. Assessment of quality of life of patients with inflammatory bowel disease residing in Southern Brazil. Arq Gastroenterol. 2010;47:285-9.

11. Costa RA, Soares HLR, Teixeira JAC. Benefícios da atividade física e do exercício físico na depressão. Rev. do Departamento de Psicologia. 2007;19:273-4. Available from: http://www.scielo.br/scielo.php?script=sci_arttext\&pid=S0104-80232007000100022

12. Batista WS, Ornellas FH. Exercício físico e depressão: relação entre o exercício físico e o grau de depressão. Rev. Brasileira de Prescrição e Fisiologia do Exercício. 2013;7:474-82. Available from: http://www.rbpfex.com.br/index.php/ rbpfex/article/view/519/528

13. Peixoto SV, Mambrini JVM, Firmo JOA, Filho AIL, Junior PRBS, Andrade FB, et al. Physical activity practice among older adults: results of the ELSI-Brazil. Rev. Saúde Pública. 2018;52(Suppl 2):5s.

14. Moradkhani A, Beckman LJ, Tabibian JH. Health-related quality of life in inflammatory bowel disease: Psychosocial, clinical, socioeconomic, and demographic predictors. J Crohns Colitis. 2013;7:467-73.

15. Mittermaier C, Dejaco C, Waldhoer T, Oefferlbauer-Ernst A, Miehsler W, Beier $\mathrm{M}$, et al. Impact of depressive mood on relapse in patients with inflammatory bowel disease: a prospective 18--month follow-up study. Psychosom Med. 2004;66:79-84 